\title{
AS RELAÇÕES ENTRE POLÍTICA EXTERNA E ECONOMIA DE DEFESA NO ESTADO NOVO (1937-1945)
}

\section{The relations between foreign policy and defense economy in the Estado Novo period (1937-1945)}

\author{
Bruna Rohr Reisdoerfer ${ }^{1}$ \\ Josiane Simão Sarti
}

\section{Introdução}

A transição de um Brasil agroexportador para um industrial pode ser percebida de modo gradual, já que a elite cafeeira detinha grande autonomia e controle sobre a política e a economia do país. Após a crise econômica de 1929, as condições que faltavam para alterar a elite dominante e trazer o grupo urbanoindustrial ao poder surgiram: diminuição das exportações de café e disputa de mercado pelos países capitalistas, por exemplo (CERVO, 2008). O presidente Getúlio Vargas, após a Revolução de 1930 e, principalmente, durante o chamado Estado Novo (1937-1945), utilizou-se de diversos instrumentos, como a barganha, para fomentar essa industrialização e, além disso, moldar uma racionalidade de segurança e defesa nacional com grande interação com as forças militares (MANI, 2011). No período de 1937 a 1945 houve: a) coesão entre a classe dirigente em torno de um Projeto de Desenvolvimento Nacional (CERVO, 2008); b) intencionalidade estatal em promover o desenvolvimento - na época, sinônimo de

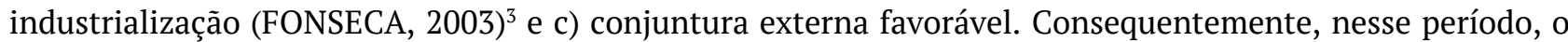
Brasil alcançou resultados significativos de barganha diplomática como a Siderurgia Nacional e equipamentos militares (MOURA, 1980).

Portanto, o trabalho tem como objetivo apresentar a relação entre política externa e economia de defesa no Estado Novo, a fim de exemplificar a importância da coesão entre ambas para o desenvolvimento nacional. Pretende-se demonstrar - através de revisão das bibliografias selecionadas - que a relação entre elas se deu por forte coesão e complementaridade - já que a política externa, utilizando-se da conjuntura

\footnotetext{
${ }^{1}$ Doutoranda do Programa de Pós-Graduação em Estudos Estratégicos Internacionais (PPGEEI - UFRGS). Mestre em Ciências Militares pela Escola de Comando e Estado-Maior do Exército. Bacharela em Relações Internacionais pela Universidade Federal do Rio Grande do Sul. Email: brunareisdoerfer@gmail.com

${ }^{2}$ Mestranda em Ciências Militares pela Escola de Comando e Estado-Maior do Exército e bolsista CAPES do Programa de Demanda Social. Bacharela em Relações Internacionais pela Universidade Federal do Rio Grande do Sul. Email: josisarti@gmail.com

${ }^{3}$ Mais sobre a intencionalidade do Estado brasileiro em prol do desenvolvimentismo, ver Fonseca (2003).
} 
interna e externa favoráveis, serviu de instrumento para a consecução e o bom desempenho da política econômica de defesa (SVARTMAN, 2008). Dentre os aspectos abordados na pesquisa, destaca-se como o Brasil, em primeira fase, utilizou sua política externa para se beneficiar das economias diversificadas de Alemanha e Estados Unidos (EUA) e, em segunda fase, como barganhou com a posição estratégica da região nordeste do país para negociar acordos com estadunidenses (MOURA, 1980).

Como metodologia de pesquisa, utiliza-se a revisão crítica de bibliografia. Segundo Knopf (2006, p. 127, 128), a revisão de literatura pode ser utilizada em três contextos: i) revisar o conhecimento já produzido sobre determinado assunto para verificar o "estado da arte" do conhecimento ou da prática, ii) utilizar a revisão bibliográfica como o primeiro passo para o desenvolvimento de um projeto de pesquisa maior a fim de contextualizá-lo no conhecimento já desenvolvido e, o seu inverso, iii) ser o componente de um relatório de pesquisa concluído, a fim de relacionar posteriormente as conclusões encontradas com o conhecimento prévio sobre o assunto. Segundo o autor, em qualquer um desses contextos, a revisão bibliográfica pode ser utilizada para acessar o conhecimento teórico e prático disponível sobre como lidar com certas questões, focando nas lições aprendidas de situações anteriores (KNOPF, 2006). Este é o objetivo da pesquisa e por isso ela foi desenvolvida através das seguintes etapas: 1) determinar o objeto a ser analisado (a saber, a política externa e a economia de defesa no Estado Novo) e qual corpo de teorias buscar. Isto é, devido ao objetivo do trabalho, detectou-se a necessidade de revisar bibliografia de Relações Internacionais acerca de política externa e de Economia acerca de economia de defesa. 2) A partir daí, buscou-se encontrar a intersecção entre as duas áreas de conhecimento no período do Estado Novo. 3) Por fim, os principais achados, das duas áreas, com validade prática para o desenvolvimento nacional foram sumarizados nas duas seções do trabalho.

Como principal instrumento de coesão da pesquisa e de análise da revisão bibliográfica sobre a política externa da época, utiliza-se a análise paradigmática de Amado Cervo (2008), por entender que ela detecta e relaciona variáveis que tratam a política externa como parte de um sistema e de um projeto nacional e não como um segmento insulado das demais políticas do Estado. Ela é, portanto, útil para entendermos a intersecção entre política externa e economia de defesa no Estado Novo e as especificidades dessa relação em comparação com outros modelos na história do Brasil. A análise paradigmática é um método que se utiliza da observação empírica para a construção de conceitos, principalmente a partir das experiências históricas em três níveis: o diplomático, o político e o das relações internacionais (CERVO, 2008, p. 65). O autor introduz os pressupostos dessa análise tendo em primeiro plano a existência da ideia de nação que o povo (ou seus dirigentes) faz de si mesmo e a visão que projeta do mundo, além da relação entre esses elementos. Em segundo plano, Cervo (2008) inclui a percepção de interesses nacionais dos dirigentes, seja em âmbitos nacionais, políticos, de segurança, econômicos e/ou culturais. Em terceiro plano, o paradigma envolve a elaboração política, condicionando tendências de médio ou longo prazos, explicando também suas rupturas. Envolve, assim, as relações entre interno e externo e a manipulação de informação para orientar a tomada de decisão e o cálculo estratégico (CERVO, 2008, p. 66). A análise 
paradigmática pretende, então, entender quais as determinações internas e os condicionantes externos, os fins da política e o peso da ideia de nação, permitindo avaliar o desempenho dos dirigentes e da sociedade organizada numa longa duração (CERVO, 2008, p. 66).

Convém explicitar que se entende por Política Econômica de Defesa ou Economia de Defesa - ainda que não exista uma conceituação consolidada na literatura - como a tentativa de se ter um olhar econômico sobre as questões de defesa (SANDLER; HARTLEY, 1995). O trabalho está estruturado da seguinte forma: após a introdução, a segunda seção apresenta o paradigma de política externa brasileira para o período adotado. A terceira seção aborda a revisão bibliográfica sobre a economia de defesa durante o Estado Novo e a quarta, sobre a política externa brasileira e as questões estratégicas da época. Por fim, seguem as considerações finais sobre os achados práticos da revisão bibliográfica acerca da relação entre política externa e economia de defesa no Estado Novo e proposta de futuras agendas de pesquisa.

\section{O paradigma do Estado Desenvolvimentista}

Apresentado o conceito de análise paradigmática de Amado Cervo, é possível compreender a importância da política externa nas negociações envolvendo defesa nacional no período do Estado Novo. Antes de entrar no paradigma desenvolvimentista, cabe apresentar o conceito de desenvolvimentismo. Esse termo apresenta robusto debate sobre sua conceituação, e Fonseca $(2015$, p. 40) o conceitua como

“[...] a política econômica formulada e/ou executada, de forma deliberada, por governos (nacionais ou subnacionais) para, através do crescimento da produção e da produtividade, sob a liderança do setor industrial, transformar a sociedade com vistas a alcançar fins desejáveis, destacadamente a superação de seus problemas econômicos e sociais, dentro dos marcos institucionais do sistema capitalista".

Assim, a nova fase da Política Externa Brasileira, a partir da década de 1930, teve impulsionamento com Getúlio Vargas e seu protótipo de Brasil, em um ambiente regional de expansão industrial (CERVO, 2008, p. 44). Nesse contexto, Amado Cervo (2008) aponta o paradoxo que a crise do capitalismo trouxera à América Latina: um processo de modernização rápido. O paradigma liberal-conservador ${ }^{5}$ de política exterior não mais combinava com a nova conjuntura externa e interna, já que as elites provenientes da economia primária foram perdendo seu poder para as lideranças urbanas - as quais cultivavam uma visão moderna de interesses e das relações internacionais (CERVO, 2008, p. 44). Além disso, o que favoreceu essa mudança foi a divisão do mundo em dois blocos, e os países fora do corredor de conflito negociavam sua adesão à guerra dos outros em troca de elementos promotores da indústria, como crédito para exportações, investimentos empresariais, fornecimento de máquinas (CERVO, 2008, p. 44).

Cervo (2008, p. 44) destaca que, até a eclosão da II Guerra Mundial, a América Latina abriu-se à competição internacional, provocando respostas de potências rivais preocupadas em assenhorear-se, não

\footnotetext{
${ }^{4}$ Para mais detalhes, ver Fonseca (2015).

${ }^{5} \mathrm{O}$ paradigma liberal-conservador é o primeiro paradigma de política externa brasileira apresentado por Amado Cervo. Esse perpassa o século XIX e se estende a 1930, destacando-se as relações econômicas a que o Brasil se submeteu: importações industriais e exportações primárias, com o prestígio externo conivente a oligarquias de dominação interna e crédito junto ao Reino Unido (CERVO, 2003, p. 11).
} 
somente do mercado de consumo, mas também do sistema produtivo local - que se expandia e se diversificava. O autor aponta os elementos que caracterizam a mudança do modelo de inserção internacional que se operava desde 1930:

\begin{abstract}
a) a inconveniência de prolongar o modelo anterior da agroexportação, que na década de 1920 cultivava o prestígio externo e procurava manter o crédito na praça de Londres e que era objeto de críticas por parte do movimento tenentista, de intelectuais e do meio político; b) a consciência que a crise do capitalismo despertou de se estar vivenciando uma fase de transição que permitia que o desenvolvimento fosse convertido em objetivo-síntese da política exterior; c) a convicção de se poder utilizar a diplomacia para alcançar resultados, a exemplo dos países de centro, então guiados pela introspecção estratégica e econômica; d) a descoberta das condições e eficiência de uma diplomacia voltada para o desenvolvimento: autonomia decisória, ação cooperativa, comércio exterior flexível sem amarras doutrinárias, subordinação da segurança aos fins econômicos e a concomitância de boas relações com os grandes e os vizinhos (CERVO, 2008, p. 44).
\end{abstract}

Para exemplificar essa mudança de paradigma, Cervo apresenta a política de comércio exterior do Brasil, orientada por três princípios: 1) aproveitar a rivalidade entre os blocos que dividiam o mundo com o intuito de aumentar a competição interna e o poder de barganha externo; 2) manter o comércio liberal com os EUA, levando esse país a decisões que aquele poder de barganha requeria; 3) realizar comércio compensado com Alemanha e Itália, mais adequado à expansão industrial nacional (CERVO, 2008, p. 45). É nesse contexto que o Brasil utilizou a política externa para barganhar e trazer a indústria nacional de base; podendo a partir daí, desenvolver uma racionalidade direcionada à defesa nacional. Além da política de comércio exterior, a II Guerra Mundial também foi fator favorável para os propósitos de desenvolvimento brasileiro e latino-americano, em que o Brasil de Vargas soube manipular habilmente essa cooperação bilateral com EUA, enquanto a Argentina insistia na neutralidade (CERVO, 2008, p. 45).

Entre 1930 e 1945, a industrialização se converteu no objetivo principal da política exterior, já que se esperava o aumento da riqueza, o provimento de meios de segurança, a abertura de oportunidades de negócios para a burguesia nacional, a expansão do emprego para as massas urbanas e a modernização da sociedade como um todo (CERVO, 2008, p. 46). Esse é o fio condutor para o entendimento do trabalho, já que as políticas industriais foram o embrião para as políticas de defesa, que na Era Vargas começaram a ter maior visibilidade e importância, principalmente considerando o paradigma do Estado desenvolvimentista.

\title{
A economia de defesa no Estado Novo (1937-1945)
}

Sob essa conjuntura, no que tange especificamente à economia de defesa, segundo Mani (2011, p. 38), a experiência da I Guerra Mundial explicitou a dependência brasileira dos países industrializados, especialmente no setor de armamentos, abrindo a discussão em torno da necessidade de uma base industrial de defesa no país. Corsi (2007, p. 249) nos lembra que a crise econômica de 1929 representou um estrangulamento externo para a economia brasileira devido à queda nos preços internacionais do café, fuga de capitais e desvalorização da moeda brasileira. A incerteza e o menor fluxo de transações comerciais advindos da crise acabaram afetando a economia de defesa através de impacto na importação de petróleo, matéria-prima industrial e armamentos (MANI, 2011, p. 38). A conjuntura interna e regional também 
pressionava por maior capacidade de defesa autônoma brasileira: a Revolução Constitucionalista de 1932 (em que as forças federais tiveram que lutar para desmobilizar o movimento); a Guerra do Chaco (19321935), em que potências estrangeiras estavam interessadas no controle de áreas de exploração de petróleo e a possibilidade de uma nova guerra mundial constranger novamente a importação de armas e produtos industrializados (MANI, 2011, p. 38). Segundo Monteiro (1938), nessa época, a Argentina já havia nacionalizado uma empresa de petróleo e de siderurgia nacional, além de possuir Forças Armadas mais equipadas.

Conforme explicitado na seção anterior acerca da conjuntura para a consolidação do novo paradigma no Estado brasileiro após 1930 - com a emergência do protagonismo de nova classe econômica Vargas percebe a importância da indústria como forma de se projetar no Sistema Internacional e assim manter o crescimento econômico e a legitimação do seu governo (CORSI, 2008). Por isso, durante o período do Estado Novo, de forma geral, havia forte coesão entre os interesses da corporação militar, dos empresários civis e de Getúlio Vargas (CARVALHO, 1999, p. 55). Segundo Carvalho (1999, p. 65), no que diz respeito à Segurança Nacional, duas figuras importantes para essa coesão foram General Góes Monteiro (Ministro da Guerra 1934-1935 e Chefe do Estado Maior do Exército 1937-1943) e Eurico Gaspar Dutra (Ministro da Guerra 1936-1945). Mesmo que pudesse não haver unanimidade, a maioria da literatura acerca do período explicita (mesmo que de forma indireta) a forte influência de seus pensamentos sobre o alinhamento entre Segurança Nacional e Economia de Defesa no projeto de desenvolvimento nacional adotado por Vargas (MONTEIRO, 1938; SILVA, 2012; RAHMEIER, 2009; SVARTMAN, 2008).

Segundo Silva (2012), a chamada Doutrina Góes Monteiro, nome dado ao conjunto de ideias de Góes Monteiro, explicita a visão que se tinha entre poder militar e econômico no período: haveria um vínculo entre Potência Militar e Potência Industrial através de um Estado forte e centralizado. Essas características podem ser encontradas nas diversas análises acerca das políticas e do modelo estatal (não só na economia de defesa) instaurado com o novo regime político adotado a partir da instauração do Estado Novo. Isso é, o desenvolvimento nacional (que passaria pela industrialização e esta pela siderurgia) era pré-condição para se alcançar a segurança nacional. Isso ocorreu pois se acreditava que somente ele poderia diminuir a dependência de fornecimento externo, trazendo maior autonomia regional para o país e maior estabilidade externa e interna (SEITENFUS, 1985; SVARTMAN, 2008; RAHMEIER, 2009; CORSI, 2007).

Segundo Silva (2012), sob essa conjuntura, a Doutrina Góes Monteiro, tinha como sua base de sustentação a defesa nacional (com uma vertente interna e externa), a promoção das indústrias de base e a exportação. Ela defendeu que houvesse uma perfeita união das Forças Armadas na organização da política. Isto é, não haveria poder civil nem militar, pois os dois se uniriam na concepção de Estado: militarização do Estado e integração das Forças Armadas na nação. De fato, 40 dos 87 interventores do Estado Novo eram militares, localizados especialmente em áreas tidas como estratégicas para a defesa nacional: Comissão Nacional de Siderurgia, Comissão Nacional do Petróleo, Companhia Siderúrgica Nacional e Fábrica Nacional de Tratores (SILVA, 2012, p. 130). Como afirma Silva (2012, p. 130), 
O que de fato a Doutrina pretendia era a aplicação sistematizada de uma política coerente, praticada em etapas, visando à disciplina do corpo social, que provocaria o desenvolvimento econômico. A consequência natural desse desenvolvimento seria a construção de uma sólida e eficiente defesa nacional.

Góes Monteiro pretendia estender as funções das Forças Armadas, defendendo que elas fossem um órgão político e com capacidade de exercer papel de força construtora da nação. Ele via a política militar como sendo totalmente interligada com todas as esferas estatais (desde o sistema de comunicações, o regime político, a educação até o sistema produtivo, enfim, todas as esferas de "existência coletiva"). Por isso, todas tinham de estar coesas (SILVA, 2012, p. 120). Segundo Silva (2012, p. 117), para Góes Monteiro, o modelo de federalismo adotado pelo Brasil quando da proclamação da república, com alta autonomia para os governos estatais impedia a construção de uma identidade nacional a fim de construir um Estado nacional forte e centralizado. Estas ideias têm convergência com o movimento tenentista da década de 1920, no qual militares brasileiros (a maioria tenentes) - influenciados pela conjuntura do pós primeira guerra mundial com descrédito das políticas liberais, forte nacionalismo, busca por centralização política e necessidade de modernização militar - defendiam a reforma do Estado brasileiro, melhores condições para a corporação militar e no fim da década de 20, começaram a desenvolver proposta de intervenção direta na vida política do país (FGV, 2018). Segundo documentos da Fundação Getúlio Vargas (FGV) (2018), mesmo que divididos, o movimento tenentista teve importante papel na revolução de 1930 que colocou Getúlio Vargas no poder, especialmente com a presença de Góes Monteiro que buscava maior proeminência do exército no novo governo. Por isso também, segundo Seitenfus (1985, p. 146-154), o golpe dado em 1937 com a implementação de uma nova constituição que dava proeminência ao executivo sob o legislativo, aumentando a centralização política e com forte influência militar foi o movimento necessário para a efetiva consolidação dos ideais da Revolução de 30 e da nova classe econômica.

Nesse sentido, Mani (2011, p. 34, 35) argumenta que, no período do Estado Novo com pressões internas e externas à estabilidade do governo Vargas, surgiu um projeto nacional no qual a coalizão entre as forças dirigentes civis e militares possibilitava o desenvolvimento de projetos e infraestrutura institucional mais duráveis e viáveis ao longo do tempo, com recursos adicionais, capacidade inovativa e suporte político. Assim, através da interpretação da bibliografia selecionada acerca das políticas econômicas de modo geral de Getúlio Vargas (visando buscar industrialização e menor dependência do investimento externo através de forte controle estatal e mecanismos de financiamento (SVARTMAN, 2008; CORSI, 2007; MANI, 2011)), pode-se concluir que sob influência da Doutrina Góes Monteiro, o Governo Vargas durante 1937-1945 desenvolveu a sua economia de defesa no sentido de construir infraestrutura nacional para a construção de armamentos e assim modernização das Forças Armadas (aspirações que serviram de incentivo ao apoio militar para a Revolução de 30 e o golpe do Estado Novo (MANI, 2011, p. 10; SEITENFUS, 1985). Como afirmou McCann (2006, p. 120 apud MANI, 2011, p. 39, tradução nossa): “Góes e Dutra deveriam dar a Vargas segurança e paz interna, e ele lhes daria armas e indústrias modernas que iriam dar suporte ao 
contínuo desenvolvimento militar"6. Foi criada, assim, a infraestrutura institucional necessária para o fomento da industrialização brasileira, tida como essencial para o desenvolvimento nacional e consequentemente para a segurança nacional. Os militares tiveram, portanto, papel importante na criação de leis e agências estatais que visavam a nacionalização da produção industrial (SVARTMAN, 2008, p. 8081). A criação da indústria nacional de petróleo e de aço eram planos militares. Foi o engenheiro militar coronel Edmundo de Macedo Soares que liderou as negociações com os EUA para a criação da Siderurgia Nacional (MANI, 2011, p. 39). A economia de defesa estava totalmente interligada com a política econômica nacional de Vargas, que utilizou a política externa como instrumento delas.

O aparelhamento completo das nossas forças armadas é uma necessidade que a Nação inteira compreende e aplaude. (...) às pequenas unidades já construídas sucederão outras, maiores e mais numerosas, e os monitores e caça-minas de hoje terão irmãos mais fortes nos torpedeiros e cruzadores de futuro próximo (VARGAS, 1940).

A colaboração civil-militar industrial envolvia que o Estado garantisse assistência, também em tempos de crise, às empresas privadas que contribuíam para a produção de defesa. Essa política visava a promoção de empresas que pudessem competir internacionalmente e criar links entre produtores nacionais (MANI, 2011, p. 39). No âmbito da cooperação civil-militar havia os programas técnicos militares abertos para civis, que contribuíam assim para o desenvolvimento de uma base tecnológica nacional e davam influência militar sob os parceiros privados civis domésticos (MANI, 2011, p. 39).

O projeto de desenvolvimento nacional de Vargas visava aumentar a capacidade industrial militar brasileira, diminuindo a dependência do capital externo, uma vez que seria dificultada a importação desses materiais em caso de guerra (SVARTMAN, 2008; CORSI, 2008). Todavia, segundo Hilton (1994, p. 113), primeiramente deveria se buscar no exterior o mínimo indispensável para alavancar tal desenvolvimento. Góes Monteiro tinha o plano de conseguir maquinário para as novas indústrias brasileiras no exterior, a fim de se tornar o mais perto de autossuficiente para materiais de guerra que pudesse. Com o intuito de financiar o reaparelhamento das Forças Armadas, o ministro da Casa Civil, General Pantaleão Pessoa, defendia a necessidade da criação de um fundo militar especial através do aumento dos impostos sobre o consumo. Através do Decreto-Lei $\mathrm{n}^{\circ}$ 1.058, de 19 de Janeiro de 1939, Vargas institucionaliza as bases para o financiamento do "Plano Especial de Obras Públicas e Aparelhamentos da Defesa Nacional” (BRASIL, 1939). Por ele ficava estruturado um orçamento para cinco anos destinado, conforme Art. $4^{\circ}$, para "a criação de indústrias básicas, execução de obras públicas produtivas e aparelhamento da defesa e segurança nacionais” (BRASIL, 1939). Ficava estipulado que cada Ministério não poderia gastar mais de 10\% do orçamento a ele destinado para despesas de pessoal. Os recursos seriam estimados anualmente e viriam de:

a) taxas criadas ou a serem criadas sobre as operações cambiais; b) lucro das operações bancárias em que o Tesouro tenha coparticipação; c) produto das cambiais provenientes do ouro metálico já adquirido e a adquirir, que exceder a 28 toneladas e for remetido para o exterior; d) produto de

\footnotetext{
${ }^{6}$ Do original: Góes and Dutra were to give Vargas internal peace and security, and he would get them the arms and the modern industries that would support continued military development (MCCANN, 2006, p. 120 apud MANI, 2011, p. 39).
} 
quaisquer operações de crédito realizadas para o fim especial de que trata o presente decreto-lei, exclusive emissão de papel-moeda; e) juros da conta especial aberta no Banco do Brasil para a centralização dos recursos previstos neste decreto-lei; f) o saldo porventura verificado com a execução do plano no exercício anterior (BRASIL, 1939).

Com a estrutura de financiamento organizada, pode-se buscar recursos no exterior. Plantas produtivas do Exército, utilizando novo maquinário da Alemanha, produziam cartuchos de artilharia, bombas, barris e partes de rifle, explosivos, fusíveis, foguetes de sinalização e máscaras de gás. Ao final dos anos 1930, o Exército estava produzindo pequeno número de aviões com projeto brasileiro que utilizavam maquinário americano (HILTON, 1994, p. 113).

Segundo Moura (1980, p. 147), os americanos se mostravam pouco dispostos a fornecer armamento aos brasileiros. A estratégia americana para a América Latina era que a região lhe suprisse com matériaprima e que mantivesse a ordem interna em cada país - assegurando a coesão do sistema americano - e não a sua participação direta no conflito. A Alemanha, por sua vez, possibilitava o comércio através de marcos de compensação. De forma simplificada, o Brasil poderia utilizar seus produtos de exportação para a compra de produtos alemães através de caixas de compensação em cada país com suas respectivas moedas. Além disso, o governo americano destinava os armamentos mais modernos às suas Forças Armadas e à exportação somente o material que estava sendo retirado de serviço (FGV, 2009). A Alemanha demonstrava maior disposição para a exportação de material bélico e de capital, pois o governo necessitava desenvolver capacidade de produção em larga escala (estava se preparando para entrar em ritmo de produção de guerra). As exportações serviriam para camuflar essa expansão (FGV, 2009).

Dessa forma, segundo Bastos (2012), em março de 1938, o governo brasileiro assinou contrato estratégico com a empresa alemã Fried Krupp. Ele previa a venda de munição, o maquinário necessário para a sua produção e a concessão do direito de produção. Previa também a venda de 1180 peças de artilharia (entre eles canhões e obuses), 646 viaturas hipomóveis para tração, transporte de munição e da guarnição das peças. O contrato previa a aquisição por parte do governo brasileiro de caminhões e tratores militares com a Krupp, com a Bussing Nag Vereeinigte Nutekraftwagen, Daimler-Benz, Henschel \& Sohn e a Locomotivfabrik Krauss \& Comp. Somente 64 peças de artilharia e 11 viaturas automotoras foram entregues. Isso se deveu ao bloqueio comercial marítimo imposto pelo Reino Unido à Alemanha em 1939, bem como da escolha brasileira por lutar ao lado dos Aliados (BASTOS, 2012).

Segundo documentos da FGV, ao mesmo tempo em que o governo brasileiro adquiriu modernas peças de artilharia de campanha e antiaérea da Alemanha, comprava dos EUA material inferior para a artilharia de costa. Após 1941, a lei americana de empréstimo e arrendamento de armas e munições serviu de arcabouço legal para os acordos de fornecimento de material bélico dos EUA ao Brasil. Em maio daquele ano, o Banco do Brasil e o governo americano assinaram um contrato de crédito de 12 milhões de dólares para a compra de armamento. De extrema importância, foram as negociações com os EUA para o financiamento e a implementação de uma indústria siderúrgica nacional no Brasil (vista como um dos pilares do desenvolvimento nacional e da defesa). Em 1940, Moura (1980, p. 154 afirma que as negociações 
ainda estavam estagnadas e as que visavam a implantação da siderurgia através da associação privada brasileira ao capital privado externo, haviam fracassado. O governo brasileiro decidiu, então, pela construção de uma indústria nacional com financiamento pela agência governamental americana EXIMBANK e pela transferência de tecnologia de empresas privadas americanas. Em setembro de 1940, foram assinados os acordos de financiamento entre os dois governos e até 1942 os EUA facilitaram a produção e o transporte do maquinário necessário para a construção da Siderúrgica Nacional brasileira (MOURA, 1980, p. 154).

Aliado a essa captação de recursos no exterior, Dutra no Ministério da Guerra, buscou destinar esforços na reformulação e ampliação das fábricas do exército já existentes. Em 1937 foi completada a construção da fábrica de projéteis de artilharia no Rio de Janeiro e a de estojos e espoletas em Minas Gerais. Ampliou-se a fábrica de canos e sabres também em Minas Gerais e a de pólvora no Rio de Janeiro, além de ter sido construída outra de pólvora de base dupla em São Paulo (1941). Ainda em 1937 foi reformado o Arsenal de Guerra e a Fábrica de Realengo, ambos no Rio de Janeiro; bem como se iniciou a construção do Arsenal de Guerra do Rio Grande do Sul. A fábrica de viaturas militares no Paraná e a de máscaras de gás no Rio de Janeiro foram remodeladas. Como efeito dos estímulos da captação de recursos no exterior, projetos de empresas privadas também foram se maturando a partir de 1943: a Companhia Brasileira de Cartuchos, a Laminação Nacional de Metais S.A. (metralhadoras Madsen), a D. F. Vasconcelos e a Companhia Nacional de Forjagem de Aço Brasileiro (Confab) (FGV, 2009).

Portanto, da análise da bibliografia selecionada, podemos dizer que o que se viu no período para a economia de defesa foi que a saída de uma economia agroexportadora para uma industrial, a fim de produzir uma realidade mais autônoma e menos dependente do exterior, passava por uma primeira fase que seria a construção de indústrias de base a fim de trazer o centro decisório econômico da época para dentro do país (FONSECA, 2003). A segurança nacional passava pela prosperidade econômica geral e pelo desenvolvimento autônomo para conter as forças internas e externas que ameaçavam a estabilidade do governo. Ou seja, a economia de defesa na época tinha como objetivo buscar o desenvolvimento nacional através da industrialização, pois essa era a condição necessária para a segurança nacional. Dessa forma, havia forte coesão interna entre as esferas dirigentes estatais (civis e militares) a fim de se buscar este objetivo. Para tanto, especificamente na área de defesa, buscaram no exterior o maquinário e os armamentos necessários para dar mínimo poder de combate ao Brasil e começar a produzir internamente (SVARTMAN, 2008). A grande influência da Doutrina Góes Monteiro no Estado Novo demonstra o porquê o objetivo síntese da economia de defesa perpassava pelo desenvolvimento nacional como um todo, pois havia o entendimento de que deveria haver esforços únicos na concepção de Estado. A seguir, demonstra-se como a política externa auxiliou nesse sentido.

\section{A política externa brasileira de 1937-1945}

Com base na contextualização anterior, ficam explícitas as condições para o novo paradigma das relações internacionais no Brasil. Há o rompimento com a diplomacia agroexportadora que se baseava na 
doutrina europeia de mercado, conferindo nova funcionalidade ao Estado e se apoiando no pensamento diplomático, na imprensa e na opinião pública (CERVO, 2008, p.72). A América Latina apresentou dinamismo econômico em direção ao mundo moderno. O Brasil recebia pressões da queda de importações e exportações (reflexos da crise econômica dos anos 1930), somado à disputa por mercado pelas potências capitalistas, à divisão do mundo em blocos e à política de boa vizinhança de Franklin D. Roosevelt (CERVO, 2008, p. 71). Esse fora um movimento latino-americano, apresentando características comuns entre diversos países, a saber:

\begin{abstract}
a) acionar a diplomacia econômica nas negociações externas; b) promover a indústria de modo a satisfazer as demandas da sociedade; c) transitar da subserviência à autonomia decisória com o fim de realizar ganhos recíprocos nas relações internacionais; d) implementar projeto nacional de desenvolvimento assertivo tendo em vista superar desigualdades entre nações; e) cimentar o todo pelo nacionalismo econômico, imitando a conduta das grandes potências (CERVO, 2008, p. 72).
\end{abstract}

No período de Getúlio Vargas no poder, sobressai principalmente o desenvolvimentismo autônomo, segundo Cervo (2008, p.74), tocado essencialmente pelas forças da nação, criador de autonomia política e de forte núcleo econômico. Gerson Moura (2012) caracteriza a política externa do Brasil na década de 1930 como uma oscilação entre uma grande potência e outra em termos comerciais, políticos e militares, denominada equilíbrio pragmático - também chamado equidistância pragmática, refere-se à postura brasileira de neutralidade em relação à Alemanha e aos EUA. Essa política trouxe diversos benefícios comerciais e aumentou o poder de barganha do Brasil nos anos seguintes (MOURA, 2012, p.51). Exemplo dessa barganha pode ser visto na visita que Osvaldo Aranha fez aos EUA, a convite do presidente Roosevelt, em 1939. Nessa visita, denominada Missão Aranha, deixou-se claro que Vargas poderia contar com os EUA e foram firmados diversos acordos, ainda que com poucos resultados econômico-financeiros (FGV, 2009). Conforme Gerson Moura,

Se houve um resultado positivo imediato, este foi o início de um processo de colaboração militar, que se consubstanciou nas visitas do general George Marshall ao Brasil, em maio de 1939, e do general Góes Monteiro aos Estados Unidos, em junho do mesmo ano. O primeiro considerou sua visita um êxito completo, enquanto o segundo foi alvo das maiores atenções das autoridades norte-americanas (FGV, 2009).

Outro evento destacável foi a reunião do Conselho de Segurança Nacional, em que se determinou a neutralidade brasileira em relação à iminente guerra europeia e uma votação decidiu continuar comprando armas dos países europeus (FGV, 2009). Mas, com a viagem de Góes Monteiro aos EUA, o general viu a oportunidade de melhorar o potencial militar brasileiro, também por temer que a Argentina se tornasse o principal aliado militar do EUA na região (FGV, 2009). Assim, quando voltou ao Brasil, Monteiro escreveu ao general Marshall afirmando a disponibilidade do Brasil em colaborar, em caso de guerra, com os EUA porém, não deixou de salientar a necessidade de armar os brasileiros e de buscar mais vantagens do que ofereciam os alemães. Como resposta, Marshall afirmou poder vender qualquer material militar excedente 
para um país amigo. Foi a partir do reequipamento militar e econômico, desde a Missão Aranha, que houve o rompimento da equidistância na política externa brasileira, resultando na aproximação e colaboração entre Brasil e EUA (MOURA, 1980, p. 156).

Cabe destacar que os EUA se interessaram em enviar tropas para o Saliente Nordestino - Natal, Recife e Fernando de Noronha - devido ao posicionamento estratégico da região (FGV, 2009). Tais esforços visavam assegurar a defesa do Nordeste, considerado essencial pelos planejadores estadunidenses (MOURA, 2012, p. 68). A área de Natal não era somente um trampolim para operações ofensivas contra a área de Dakar, na África. Mas era a base territorial que poderia, caso mantida segura pelos EUA, ter controle efetivo das costas leste e norte da América do Sul, trazendo proteção a ataques do Eixo a partir do Atlântico, além da área vital do Caribe, incluindo o canal do Panamá (MOURA, 1980, p. 93).

Os EUA mediaram disputas do Brasil com o Reino Unido - o governo brasileiro tentou transportar materiais bélicos comprados na Alemanha, a bordo do navio Siqueira Campos. Porém, o governo britânico manteve seu bloqueio e impediu que o navio partisse para o Brasil. Além desse incidente, outro navio brasileiro, denominado Buarque, fora inspecionado e dele retirados 70 caixotes (MOURA, 2012, p.71). Mais um episódio ocorreu, dessa vez envolvendo o navio a vapor Bagé, o qual também carregava material bélico de origem alemã. Esse chegou a Lisboa para transferir a carga para o Siqueira Campos, que já tinha partido, ficando em Lisboa até que se chegasse a um acordo com o Reino Unido (MOURA, 2012, p.71)

Moura (2012, p.72) afirma que ainda que essas mediações dos estadunidenses não tenham alterado significativamente as relações militares entre Brasil-EUA, elas abriram caminhos para uma série de iniciativas, como acordos e compras de materiais estratégicos. Em suma, as tentativas dos EUA de obter quaisquer concessões brasileiras enfrentavam grandes rejeições, ao mesmo tempo em que os esforços estadunidenses de obter definições e planos claros para a defesa do Nordeste no âmbito da Comissão Mista Brasil-EUA enfrentavam a insistência brasileira de se ter garantias sobre aeronaves e armamentos providenciados pelos americanos (MOURA, 2012, p. 74).

Apesar da visão de Gerson Moura (2012) estar bem delineada e ser a base de parte desse artigo, é necessário destacar o debate acerca dessa visão, conforme abordagem de Bueno (2006). Além dessa interpretação amparada na história, existe a versão dos economistas, que consideram a interpretação histórica errônea, superestimando o papel da Alemanha nos ganhos econômicos para o Brasil. Em resumo, existe a necessidade de corrigir indicadores sobre a balança comercial Brasil-Alemanha dos anos 1930 por parte dos historiadores, mas isso não desqualifica a noção de pragmatismo construída (BUENO, 2006). Bueno (2006, p. 189) apresenta em sua conclusão que tanto historiadores quanto economistas se equivocaram sobre a proposta alemã, e que somente foi oferecido a usina siderúrgica e a intensificação do comércio com o Brasil para depois do término da guerra.

Apresentada essa ressalva, pode-se verificar, então, que o presidente Getúlio Vargas se utilizou da diplomacia e da política externa, primeiramente mantendo a equidistância pragmática entre Alemanha e EUA, barganhando com ambas até o momento em que se alinhou aos EUA e entrou na II Guerra Mundial. Dessa forma, desenvolveu a indústria internamente, trouxe investimentos externos e consolidou seu projeto 
de desenvolvimento nacional - tendo negociado habilmente, ainda que alguns acordos não tenham sido tão efetivos. Ainda nesse período, a defesa nacional se mostrou como variável dependente dos objetivos de desenvolvimento, concebidos como expansão industrial (CERVO, 2008, p. 128).

Nota-se que o aumento da barganha com os EUA ocorreu principalmente na fase do equilíbrio pragmático, já que os estadunidenses viam a necessidade de construir seu sistema de poder. Assim, os maiores ganhos de política externa de Vargas ocorreram quando da quebra desse equilíbrio, justamente para servir aos países Aliados (MOURA, 1980, p.185). Ainda, o peso político das Forças Armadas no Estado Novo explica o motivo de o reaparelhamento militar ter grande protagonismo nas reivindicações de política externa, criando nexo entre economia de defesa e política externa.

\section{Considerações Finais}

Pode-se concluir que no período de 1937-1945 a segurança e a defesa nacionais passaram a ser vistas como a articulação de todas as esferas de poder do Estado. A Doutrina Góes Monteiro influenciou na articulação da estratégia militar, política, econômica e psicossocial a fim de se alcançar o objetivo nacional, representados pelo desenvolvimento industrial, unidade nacional, segurança e prosperidade crescente. Nesse sentido, a política econômica de defesa se sobressaiu como um dos pilares do projeto de desenvolvimento nacional encabeçado por Vargas, estando fortemente interligado com a política externa. Segundo Visentini (2009, p. 53), a Era Vargas iniciou uma nova etapa da política externa brasileira, ao introduzir a problemática da subordinação das relações exteriores às necessidades do projeto de desenvolvimento industrial. Portanto, detectou-se que a forte relação entre a política externa e a economia de defesa durante o Estado Novo trouxe ganhos substanciais ao país, lançando as bases para o que se consolidou nos períodos posteriores no Brasil.

A Política Externa foi utilizada para fomentar, através de captação de recursos estrangeiros, o desenvolvimento econômico do país visto como essencial para diminuir o atraso histórico frente às grandes potências. O desenvolvimento era sinônimo de indústrias de base e a segurança do país perpassava pelo desenvolvimento industrial. Para tanto, buscaram no exterior o maquinário e os armamentos necessários para dar mínimo poder de combate ao Brasil e começar a produzir internamente. Nesse sentido, a Política Externa foi de extrema importância, pois conseguiu manter, por determinado período, a barganha com Alemanha e EUA simultaneamente, caracterizada pela equidistância pragmática. Depois, alinhou-se aos americanos e colheu os resultados das negociações diplomáticas. Como afirma Moura (1980, p. 188).

O alinhamento não é um resultado automático da economia ou da geografia: é um processo longamente negociado e isso supõe alguma força por parte do aliado subordinado. Sé é verdade que os EUA determinaram o momento das decisões, estas não se realizaram segundo sua exclusiva vontade.

Percebe-se, então, que a coesão entre Política Externa e Economia de Defesa foi extremamente importante para que o país alcançasse os objetivos nacionais da época, pois uma esfera serviu de instrumento da outra. Por conseguinte, o presente trabalho pode servir de ponto de partida para aprofundar 
no debate sobre a construção de uma Grande Estratégia Brasileira que seja duradoura, a fim de que se possa alcançar resultados efetivos para os interesses nacionais. Atualmente, percebe-se uma descontinuidade do que se entende por projeto de nação, justamente por políticas que são descontinuadas ou alteradas. Essa possível agenda de pesquisa engloba não só questões de segurança e de defesa, que são determinantes para a proteção da soberania brasileira e afirmação dos instrumentos de poder, mas também de Ciência Política, fora do escopo deste trabalho e que também apresenta relevância para o entendimento da formação do Estado brasileiro e seus reflexos para as relações contemporâneas.

\section{REFERÊNCIAS}

BASTOS, Expedito Carlos Stephani. Motorização no Exército Brasileiro 1906-1941. Juiz de Fora: O Autor e UFJF/Defesa, 2012. Disponível em: <https://issuu.com/defesa/docs/motoriza o_release_baixa>. Acesso em: 28 nov. 2016.

BRASIL. Decreto-lei $n^{o}$ 1058, de 19 de janeiro de 1939. Plano Especial de Obras Públicas e Aparelhamentos da Defesa Nacional. Rio de Janeiro, 1939. Disponível em: <http://www2.camara.leg.br/legin/fed/declei/1930-1939/decreto-lei-1058-19-janeiro-1939-349207publicacaooriginal-1-pe.html>. Acesso em: 29 set. 2016.

BUENO, Ironildes. Estados Unidos versus Alemanha: o falso dilema sobre o início da indústria de base brasileira. Revista Cena Internacional, Brasília, v. 8, p. 171-192, 2006.

CARVALHO, José Murilo de. Vargas e os Militares: Aprendiz de Feiticeiro. In: D’ARAUJO, Maria Celina (Org.). As Instituições Brasileiras da Era Vargas. Rio de Janeiro: Ed. UERJ: Ed. Fundação Getúlio Vargas, 1999.

CERVO, Amado Luiz. Inserção Internacional: formação dos conceitos brasileiros. São Paulo: Saraiva, 2008.

CERVO, Amado Luiz. Política exterior e relações internacionais do Brasil: enfoque paradigmático. Revista Brasileira de Política Internacional, Rio de Janeiro, v. 2, n. 46, p.5-25, out. 2003.

CORSI, Francisco Luiz. Política Externa e Desenvolvimento no Estado Novo. Locus, Revista de História, Juiz de Fora, v. 13, n. 2, p. 247-260, 2007. Disponível em: $<$ https://locus.ufjf.emnuvens.com.br/locus/article/view/2232>. Acesso em: 16 jan. 2018.

Política externa, projeto nacional e política econômica ao final do Estado Novo. Política \& Sociedade, [s.l.], v. 7, n. 12, p.67-93, 23 out. 2008. Universidade Federal de Santa Catarina (UFSC). http://dx.doi.org/10.5007/2175-7984.2008v7n12p67. Disponível em: <https://periodicos.ufsc.br/index.php/politica/article/view/2175-7984.2008v7n12p67>. Acesso em: 16 jan. 2018.

FGV. Movimento Tenentista. In: FGV CPDOC. A Era Vargas: dos anos 20 a 1945. [2018]. Disponível em: <http://cpdoc.fgv.br/producao/dossies/AEraVargas1/anos20/CrisePolitica/MovimentoTenentista>. Acesso em: 16 jan. 2018.

Verbete Eurico Gaspar Dutra. In: FGV CPDOC. Dicionário. [2009]. Disponível em: <http://www.fgv.br/cpdoc/acervo/dicionarios/verbete-biografico/dutra-eurico-gaspar>. Acesso em: 29 set. 2016. 
FONSECA, Pedro C. D. Desenvolvimentismo: a construção do conceito. Textos para Discussão IPEA, 2015. Disponível em: <http://repositorio.ipea.gov.br/bitstream/11058/4580/1/td_2103.pdf〉. Acesso em: 16 jan. 2018.

Sobre a intencionalidade da política industrializante do Brasil na década de 1930. Revista de Economia Política, São Paulo, v. 23, n. I (89), jan-mar. 2003.

HILTON, Stanley E. The Armed Forces and Industrialists in Modern Brazil: The Drive for Military Autonomy, 1889-1945. In: RODRIGUEZ, Linda A. Rank and Privilege: The Military and Society in Latin America. Wilmington: Scholarly Resources, 1994.

KNOPF, Jeffrey W. Doing a Literature Review. PS: Political Science and Politics, v. 39, no. 1, jan (2006), p. 127-32. Disponível em: <http://www.jstor.org/stable/20451692>. Acesso em: 15 jan. 2018.

MCCANN, Frank D. The Military and the Dictatorship: Getúlio, Góes, and Dutra. In: HENTSCHKE, Jens R. Vargas and Brazil: New Perspectives. New York: Palgrave Macmillan, 2006. p. 109-41.

MANI, Kristina. Military Entrepreneurs: Patterns in Latin America. Latin American Politics and Society, Miami, v. 53, n. 3, p. 25-55, ago. 2011. Disponível em: <https://new.oberlin.edu/dotAsset/4690465.pdf>. Acesso em: 13 set. 2016.

MONTEIRO, Pedro Aurélio de Góes. Estudo de Góes Monteiro sobre a capacidade, as necessidades e o objetivo do Exército brasileiro. Rio de Janeiro, 1938.

MOURA, Gerson. Autonomia na Dependência. A Política Externa Brasileira de 1935 a 1942 . Rio de Janeiro: Editora Nova Fronteira, 1980.

. Relações exteriores do Brasil 1939-1950 - Mudanças na natureza das relações Brasil-Estados Unidos durante a Segunda Guerra Mundial. Brasília: FUNAG, 2012.

RAHMEIER, Andrea Helena Petry. Relações diplomáticas e militares entre a Alemanha e o Brasil: da proximidade ao rompimento (1937-1942). Tese (Doutorado em História). Pontifícia Universidade Católica do Rio grande do Sul, Porto Alegre, 2009.

SANDLER, Todd; HARTLEY, Keith (eds.). Handbook of Defense Economics. Amsterdam: Elsevier, 1995.

SEITENFUS, Ricardo Antônio. O Brasil de Getúlio Vargas e a Formação dos Blocos: o processo de envolvimento brasileiro na Segunda Guerra Mundial. São Paulo: Companhia Editora Nacional, 1985.

SILVA, Luiz Carlos Tomaz. A liderança do General Góes Monteiro nas transformações políticas do Exército, na Era Vargas. 2012. 196 f. Dissertação (Mestrado) - Curso de Mestrado em Ciências Militares, Escola de Comando e Estado-maior do Exército, Rio de Janeiro, 2012.

SILVA, Golbery do Couto e. Conjuntura Política Nacional: o Poder Executivo e Geopolítica do Brasil. 3. ed. Rio de Janeiro: J. Olympio, 1981.

SVARTMAN, Eduardo Munhoz. O pragmatismo brasileiro na cooperação militar com os Estados Unidos nas décadas de 1930 e 1940. Estudos Ibero-Americanos, v. XXXIV, n. 1, p. 76-91, 2008.

VARGAS, Getúlio. No limiar de uma nova era: Discurso Pronunciado a Bordo do Encouraçado Minas Gerais, Capitânea da Esquadra Nacional, a 11 de Junho de 1940. Rio de Janeiro: Biblioteca da Presidência da $\quad$ República, $1940 . \quad$ Disponível em: $<$ http://www.biblioteca.presidencia.gov.br/presidencia/ex-presidentes/getuliovargas/discursos/1940/21.pdf>. Acesso em: 29 set. 2016. 
VISENTINI, Paulo Fagundes. Relações Exteriores do Brasil II (1930-1964): o nacionalismo, da Era Vargas à Política Externa Independente. Petrópolis: Vozes, 2009.

Recebido em 22 de maio de 2017. Aprovado em 05 de janeiro de 2018. 


\title{
RESUMO
}

O artigo apresenta revisão bibliográfica sobre a importância da Política Externa e de Defesa para o desenvolvimento nacional durante o Estado Novo (1937-1945). Conclui-se que, nesse período, essa relação se deu por forte coesão e complementaridade entre ambas.

Palavras-chave: Política Externa; Economia de Defesa; Estado Novo.

\begin{abstract}
The article presents bibliographic review about the importance of the Foreign and Defense Policies to national development during the Estado Novo period (1937-1945). It is concluded that, in this period, this relation has developed through strong cohesion and complementarity between those previously mentioned.
\end{abstract}

Key-words: Foreign Policy; Defense Economy; Estado Novo. 